\title{
Café Müller y La consagración de la primavera en tensión.
} Una lectura del teatro danza

\section{de Pina Bausch desde la filosofía de Walter Benjamin, y viceversa}

\author{
LUDMILA HLEBOVICH Universidad Nacional de La Plata - CONICET, Argentina \\ ORCID 0000-0002-8885-7919 \\ lhlebovich@fahce.unlp.edu.ar
}

\section{Resumen}

Café Müller y La consagración de la primavera conforman dos obras del Tanztheater Wuppertal, creado por Pina Bausch, que suelen presentarse juntas en una única función. Es posible notar que esta conjunción no se organiza tanto por lo que tienen en común como por aquello que las diferencia y tensiona. En este artículo propongo analizar dichas tensiones desde el pensamiento de Walter Benjamin teniendo en consideración que ambos autores, apoyados en el teatro brechtiano, apuntan a deshacer la ilusión frente a la crisis de la experiencia y de la narración. A través de la interrupción y la fragmentación toman distancia del expresionismo y del intento de recuperar una experiencia perdida resguardada en la interioridad. Cabe entonces la pregunta por si es posible un modo de experiencia y de narración sin continuidad. Desde aquí propongo comprender las distintas operaciones que forjan un modo urbano de narración en la obra de Bausch en relación con la situación de la experiencia en los espacios citadinos. Asimismo, teniendo en cuenta que tradicionalmente la filosofía ha desatendido a la danza, este recorrido permite poner de relieve y realizar una lectura de algunas de las esporádicas referencias de Benjamin a dicha forma del arte.

Palabras clave: experiencia / narración / ilusión / interrupción / teatro danza

Café Müller and The Rite of the Spring in tension. A reading of Pina Bausch's dance theatre from Walter Benjamin's philosophy, and vice versa Abstract

Café Müller and The Rite of Spring are two pieces of the Tanztheater Wuppertal, created by Pina Bausch, which are usually presented together in a single evening. It is possible to notice that this conjunction is not organized by what they have in common but by their differences and tensions. In this article, I aim to analyse these tensions from Walter Benjamin's thought, considering that both Bausch and Benjamin, based on Brechtian theatre, aim to undo the illusion against the crisis of the experience and storytelling. Through interruption and fragmentation, they take distance from expressionism and from the attempt to recover a lost inward experience. The

Recibido: 28/2/2021. Aceptado: 8/3/2021

Para citar este artículo: Hlebovich, L. (2021). Café Müller y La consagración de la primavera en tensión. 
following question then arises: is it possible a mode of experience and storytelling without continuity? I suggest a reading of the different manoeuvres that help forge an urban mode of storytelling in Bausch's work concerning the situation of experience in urban spaces. Likewise, taking into account that philosophy has traditionally neglected dance, this reconstruction allows to highlight and interpret some of Benjamin's sporadic references to this art form.

Key words: experience / storytelling / illusion / interruption / dance theatre

«Leer lo nunca escrito». Esa lectura es la más antigua: leer antes del lenguaje, a partir de las vísceras, o de las danzas o de las estrellas.

Walter Benjamin

¿Por qué la danza no puede ser materia de pensamiento?

Pina Bausch

El teatro danza de Wuppertal, a cargo de Pina Bausch desde 1973 hasta 2009 —año de su muerte- - se caracteriza por dar un giro en el desarrollo de la danza alemana. Bausch, en cercanía a Kurt Jooss, crea su propio «lenguaje coreográfico» basado en su «principio de trabajo» (Koldehoff y Pina Bausch Fundation, 2016:24 y 236). ${ }^{1}$ Sin embargo, este giro no deja de involucrar de cierto modo un retorno de algunas exploraciones centrales del teatro danza alemán luego de que el nazismo y la Segunda Guerra Mundial redujeran notoriamente la actividad en el área (cfr. Servos, 2017:25 26). En este marco, se observa que Bausch reanima algunos de los problemas cruciales de la tradición de teatro danza y la tradición expresionista, entre ellos el de la representación desde el vínculo entre coreógrafa y bailarines así como la expresividad de los sentimientos o emociones (Gefühle). En la medida en que Bausch retoma estos problemas, es posible trazar una relación, no exenta de contrapuntos, entre su recorrido y el de Mary Wigman, referente del expresionismo alemán en danza.

La particularidad del giro bauschiano puede leerse en el hecho de que dos obras notoriamente distintas, Café Müller y La consagración de la primavera, suelan presentarse hasta la actualidad en una misma función. Es posible observar que esta conjunción no se organiza tanto por lo que tienen en común como por lo que las diferencia y tensiona. Si bien en ambas obras la expresión de las emociones cumple un rol central, en cada una de ellas Bausch toma una postura distinta con respecto a los problemas de la experiencia, de la representación y de la narración. A partir de estas tensiones sugiero una lectura desde el pensamiento de Walter Benjamin teniendo en consideración que tanto Benjamin como Bausch, apoyados en el teatro brechtiano, apuntan a deshacer la ilusión frente a la crisis de la experiencia y de la narración. A través de la interrupción y la fragmentación ambos autores buscan tomar distancia del expresionismo y del intento de recuperar una experiencia perdida resguardada en la interioridad. En esta situación cabe la pregunta de si es posible un modo de experiencia y de narración sin continuidad. Desde aquí propongo comprender las distintas operaciones que forjan un modo urbano de narración en la obra de Pina Bausch en relación con la situación de la experiencia en los espacios citadinos. Asimismo, teniendo en cuenta el descuido que tradicionalmente ha tenido la filosofía con 
respecto a la danza, este recorrido permite poner de relieve y realizar una lectura de algunas de las esporádicas y marginales referencias de Benjamin a esta forma del arte, puntualmente a los Ballets Rusos y al expresionismo de Wigman. ${ }^{2}$

\section{La consagración de la primavera}

En 1975 Bausch estrena La consagración de la primavera (Frühlingsopfer) en la ciudad de Wuppertal siguiendo de cerca el orden y la historia según el libreto original. ${ }^{3}$ La versión original es estrenada en 1913 en el Théâtre des Champs-Elisées con composición musical de Igor Stravinsky y coreografía de Vatzlav Nijinsky. Stravinsky formula la propuesta de esta obra alrededor de 1910, época en la que los Ballets Rusos cuentan con gran éxito en Europa, mostrando un primitivismo musical y una imagen de la Rusia pagana que genera un encantamiento general en el público parisino y londinense. Quien fomenta este gran proyecto es Sergei Diaghilev, por lo que usualmente se lo llama el «empresario» de los Ballets Rusos.

Las vicisitudes de esta obra han hecho que su música trascienda y se conserve con más precisión que su coreografía. Bausch, para su versión, si bien no podría ni pretende reponer con exactitud la coreografía original, sigue el orden de las dos partes del libreto: la primera se titula «El beso de la tierra» y la segunda «El gran sacrificio» (cfr. Godínez, 2017:78). En la versión bauschiana el suelo del escenario se encuentra completamente cubierto de una capa de tierra húmeda. Su olor se siente desde las butacas del teatro. La iluminación es tenue y genera un clima cálido. La primera imagen que se arma es la de una mujer que, tendida sobre la tela de un vestido rojo en la tierra, se mueve levemente como si estuviera en un sueño que la inquieta. Aparecen otras mujeres que se desplazan en distintas direcciones. Todas están descalzas y llevan unos vestidos livianos de un color claro que deja traslucir el cuerpo. La mujer que antes estaba tendida se levanta, toma el vestido rojo entre las manos, extiende con cautela los brazos hacia el frente y sin perderlo de vista lo deja caer al suelo. Se aleja y se une al grupo de mujeres para bailar al unísono una danza. Con las piernas abiertas, semiflexionadas y el peso del cuerpo cayendo sobre los pies que se hunden en la tierra todas las mujeres levantan los brazos entrelazando arriba los dedos de las manos y, como si fueran a cortar algo con precisión y fuerza, los lanzan entre las piernas hasta encorvarse y hundir la cabeza en el pecho. Entran a escena los hombres con el torso desnudo y pantalones de color oscuro. Se dan distintas danzas circulares y la repetición de las secuencias de movimientos despliega las imágenes y envuelve a quienes bailan y al público en el ritmo.

Es posible notar que Bausch recupera también la "complicidad musical que imaginó Stravinsky», quien, a través de una «desintegración rítmica», rompe con la periodicidad de los acentos (Godínez, 2017:84; Abad Carlés, 2018:189). En su momento, la particularidad de su música llevó a que Diaghilev acudiera a la escuela del referente expresionista Émile Jaques-Dalcroze trazando de este modo un vínculo íntimo entre La consagración y el expresionismo. La investigación de Dalcroze era necesaria para la formación rítmica de Nijinsky en su labor coreográfica. Dalcroze, con quien también estudia Wigman, desarrolla un método basado en principios eurítmicos sosteniendo que la música debe tener equivalentes físicos. Caracteriza a la música por tres elementos: el sonido, el ritmo y la dinámica. Los últimos dos dependen por completo del movimiento físico y, por tanto, tienen su respuesta en el sistema muscular. Esto lo lleva a crear un sistema complejo de relaciones entre la música y su correspondiente en el movimiento: «El propósito de mis enseñanzas es hacer que mis alumnos puedan decir al final de sus estudios no 
"yo sé" sino "yo siento", y también crear en ellos el deseo de expresarse a sí mismos» (citado en Abad Carlés, 2018:227). La expresión del individuo se impone así frente a la forma, es decir, la forma no es sino la expresión externa de algo interior.

En la segunda parte de La consagración de Bausch, las mujeres forman un único grupo que camina en círculos. Desde allí una a una van saliendo con el vestido rojo entre las manos, acercándose a un hombre que las espera y volviendo lo más pronto posible al círculo. Una de ellas es tomada como elegida, es decir, como heroína y víctima. El hombre la desnuda, le coloca el vestido rojo, la toma de los hombros y la conduce por el espacio hasta que con un empujón la deja en el centro de la escena. Luego de un momento en quietud, ella, con la cabeza hacia abajo, una mano abierta a la altura del pecho y otra justo abajo a la altura del estómago, cae al suelo. Pero rápido se incorpora y allí comienza el último solo en el que la elegida baila hasta desmoronarse definitivamente en la tierra.

Desde una coreografía que sigue la narración dramática, esta obra busca la compenetración de quienes bailan y del público con los acontecimientos escénicos y, en especial, con la figura de la elegida. Bausch lleva adelante esta búsqueda haciendo énfasis en la continuidad del sentimiento de horror ante el sacrificio y la muerte: «Cuando corrés, esto tiene que venir más, más de los sentimientos... [de] este tipo de horror» le explica Bausch a Kyomi Ichida durante un ensayo del solo de la elegida (Bausch, 2013:49, cursivas agregadas). La expresividad corporal de los sentimientos característica de La consagración involucra también un posicionamiento respecto a la discusión sobre la representación, esto es, «acabar con la idea de que la danza representa, para partir de la premisa de que la danza es» (Abad Carlés, 2018:230, cursivas agregadas). En este marco Bausch asume una relación con quienes bailan de modo tal que indica, apoyada en una música y un libreto, cómo llevar adelante ciertos movimientos y qué emociones se precisan. Por ejemplo, si se atiende a la grabación del ensayo, cuando Bausch dice «esto», en la cita anterior, se puede ver que, al mismo tiempo, le muestra a Ichida cómo caminar hacia atrás con el pecho hundido y los brazos extendidos hacia adelante, balanceando así el cuerpo para no caer. Por su parte, Josephine Ann Endicott, quien ha bailado para el Tanztheater Wuppertal desde sus orígenes, comenta que Bausch ensaya en su oficina particular el solo de la elegida en el que «baila hasta morir» y, para la ocasión del estreno, se lo enseña a Marlies Alt (Endicott, 2012:70). Endicott recuerda la primera vez que ve el solo de la elegida en la escena en la que ella misma baila:

Nadie de nosotros sabía cómo «la elegida» bailaría para morir. En ese tiempo lo bailaba Marlies. La coreografía se fue desarrollando y ahí estábamos, transpirados y agitados, todo el espacio temblaba cuando veíamos a Marlies luchar contra la muerte. Fue extraordinario; fue tan aterrador que apenas pude verlo. Me decía a mí misma que ella realmente iba a morir. Entonces me tuve que bajar del escenario sola. Mis pies estaban como idos. Mis ojos estaban clavados en Marlies. Entonces, al final, ella cae, muere. ¿Quién sabe si ella no estaba realmente muerta? No lo pude soportar y corrí fuera de la escena llorando —así de extraordinario fue. La consagración es absolutamente única. (2012:70)

Como observa Servos, la escenografía también tiene un rol fundamental en la generación del clima de compenetración: 
En la danza-teatro de Pina Bausch nada es «como si»; los bailarines no fingen su agotamiento: es real, producto de la resistencia opuesta por una capa de tierra que les llega al tobillo. La energía que La consagración de la primavera exige de los bailarines conmueve de inmediato al público. El esfuerzo no se esconde tras una máscara sonriente; se oye en la respiración dificultosa de los actores. La vehemente presencia sensorial que logran estos con el trabajo corporal dota a la historia de corporeidad y permite vivir de cerca el sacrificio. (2017:55)

Endicott constata la observación de Servos cuando comenta cómo la tierra es determinante de las sensaciones y los movimientos en el escenario (2012:71). Este trabajo escenográfico está a cargo del primer marido de Bausch, Rolf Borzik. Los decorados son casi inexistentes pero la tierra se pega a las pieles transpiradas de los cuerpos de quienes bailan esa danza frenética. El espacio escénico dialoga constantemente con el movimiento, algo que se encuentra en todas las obras de Bausch y que, puntualmente en esta obra, direcciona y propicia la compenetración.

Ahora bien, en el estreno de La consagración de Bausch esta obra conforma una misma función con las obras Viento del oeste (Wind von West) y La segunda primavera (Der zweite Frühling). Y aquí es importante notar que según el registro de Servos estas últimas se estructuran desde una lógica más cercana al teatro danza. Es posible ver así que Bausch configura la función de modo tal que las distintas obras se hallan en tensión. La última parte, La consagración, no tarda en presentarse como obra independiente y luego junto a Café Müller. Sobre la base de lo señalado, considero esa combinación como una búsqueda por parte de Bausch de generar una tensión entre ambas obras de modo similar a como en un principio lo explora con Viento del oeste y La segunda primavera. Para dar cuenta de esto es preciso detenerse en Café Müller.

\section{Café Müller}

Café Müller es estrenada en 1978 en una función para la que Bausch invita a los coreógrafos Gerhard Bohner, Gigi-Gheorghe Caciuleanu y Hans Pop a presentar producciones independientes que en ese entonces no tienen título propio sino que se unen bajo el de «Café Müller». Los coreógrafos establecen algunos puntos de partida que pueden combinarse a criterio de cada uno: un café, oscuridad, cuatro personas, alguien espera, alguien se desmaya, alguien le ayuda a levantarse, entra una joven pelirroja y todo se queda en silencio (cfr. Servos, 2017:103).

La obra de Bausch tiene una duración de aproximadamente 45 minutos. La escenografía arma un café con un decorado gris y parco con una iluminación tenue. El escenario está lleno de mesas y sillas vacías, en el fondo hay una puerta giratoria. Al principio de la obra aparecen dos mujeres vestidas con camisones blancos casi transparentes, descalzas. Caminan dando pequeños pasos con los ojos cerrados, los brazos hacia abajo y las palmas de las manos vueltas hacia el frente. La cantidad de sillas y mesas impide desplazamientos amplios. Las mujeres se van chocando levemente con las sillas. Distintas lecturas que se han realizado sobre estas últimas figuras generalmente las comparan con «sonámbulas», «ciegas», personas en trance e «inmersas en el mundo interior de sus sentimientos», sin conciencia de su entorno «danzando entre sombras o fantasmas» (Godínez, 2017:103; Servos, 2017:105). Por otro lado, y en tensión con dichas figuras, entra por la puerta giratoria una mujer con peluca roja y con los ojos abiertos que recorre a paso apurado todo el espacio y sale de escena. Una de las mujeres con ojos cerrados comienza a lanzarse en distintas direcciones mientras suena un aria de Henry Purcell y un hombre de traje 
oscuro, calzado y con los ojos abiertos corre las sillas y mesas para evitar que aquella se golpee. En el estreno de la obra el rol de este hombre lo hizo el mismo escenógrafo Rolf Borzik que, al mismo tiempo, se interpreta a sí mismo mientras arma el espacio.

Otra escena de Café Müller, quizás la más célebre de toda la obra de Bausch, es la del abrazo. Una de las mujeres se topa con otro hombre con pantalón y camisa, pero también descalzo. Se abrazan suavemente como si se reconocieran. Interrumpe el abrazo un tercer hombre vestido de traje que se acerca, quita uno a uno los brazos entrelazados de la pareja y coloca las cabezas enfrentadas en posición de beso. La escena queda sin música y se pueden escuchar los sonidos de sus movimientos. El tercer hombre carga a la mujer y la deja entre los brazos del segundo. Terminada la tarea se va, pero mientras se aleja los brazos del segundo hombre se aflojan hasta que la mujer cae al suelo; ella se levanta rápidamente y vuelve al abrazo inicial. El tercer hombre regresa, desenlaza los brazos, ubica las cabezas en posición de beso, levanta a la mujer y la lleva entre los brazos del segundo hombre. Pero mientras se aleja la mujer cae y rápidamente retorna al abrazo. El tercer hombre vuelve pronto y reitera sus acciones a un ritmo más ágil pero la mujer vuelve a caer y abrazar al segundo hombre. Los movimientos se repiten una y otra vez y el cuerpo de la mujer se disputa entre sus fuerzas, las de los hombres y la del suelo. El aumento de la velocidad en la repetición genera que la agitación, el sonido de los pasos y las caídas contra el piso sean cada vez más audibles. El tercer hombre ya no vuelve, pero aun así la pareja continúa haciendo los movimientos que aquel conducía. Se puede ver la fuerza, cierta inestabilidad y cansancio a la vez que los movimientos cuyos trayectos antes podían distinguirse ahora se juntan armando un solo continuo que la pareja repite y repite hasta, finalmente, volver al abrazo inicial.

A partir de las escenas mencionadas noto que en esta obra se pone en tensión la danza de las bailarinas inmersas en su interioridad y la de los bailarines que llevan a escena gestos que parten de su propia cotidianidad, como armar el escenario, a la vez que toman postura frente a lo que está sucediendo. Además, la tensión entre el abrazo de la pareja y la interrupción del tercer hombre, que se repite hasta el cansancio, trastoca el sentido que pudo haber generado la imagen inicial del abrazo. Asimismo, existe un contrapunto entre La consagración y Café Müller que puede ser leído, según propongo, teniendo en consideración que las exploraciones de Bausch se ubican en un contexto de crisis del movimiento, de la danza y de la experiencia que encuentra en la fragmentación un modo de elaboración (cfr. Lepecki, 2008). La crisis de la experiencia y del movimiento atraviesa todo el trabajo de Bausch y se sintetiza en su célebre idea de que no le interesa cómo se mueve la gente sino qué la mueve o por qué se mueve:

¿Por qué hacemos lo que hacemos? ¿Por qué bailamos después de todo? Es bastante peligroso, hacia dónde estamos dirigiéndonos en este momento y en los últimos años. Todo es rutina y ya nadie sabe por qué nos movemos. Es simplemente una extraña vanidad la que hace que los hombres siempre continúen como si nada. (PB, 2016:37)

Estas ideas podrían ser interpretadas teniendo en cuenta la influencia del expresionismo en tanto corriente que plantea que el contenido, el qué, se impone frente a la forma, el cómo. En el ámbito de la danza expresionista alemana, Wigman define a la danza con los siguientes términos: 
un lenguaje vivo que habla del hombre — un mensaje artístico que se lanza al más allá de la realidad a fin de hablar, por así decirlo, a un nivel más elevado, con imágenes y alegorías, de las emociones más íntimas del hombre (...) Porque el hombre es a la vez emisor e intermediario, ya que el medio de expresión es el cuerpo humano; porque el movimiento natural de éste es el material de la danza (Wigman, 2002:17, las cursivas son agregadas)

En esta línea, Wigman sostiene que la fuerza creativa consiste en un secreto de selección: «¿Qué sería la creatividad artística si no hubiera el secreto de la selección?» (2002:97). El «talento artístico» depende de la «naturaleza» y el «bailarín es portador y mensajero del arte de la danza» (99). Según Wigman, ella transforma a los bailarines en «instrumentos», en «cuerpos armoniosos», «ejemplares en todos los aspectos» para que expresen las emociones más profundas de la directora (49). Se trata así de un realismo que, a su vez, busca transmitir un «mensaje artístico que se lanza más allá de la realidad» (17).

Resulta notorio que Wigman enfatiza la relación entre expresión, interior y naturaleza énfasis que remite a su formación con Rudolf von Laban cuando este dirige las danzas corales en el Monte Verità-. Por su parte, la exploración de Bausch en torno al movimiento presenta ciertas diferencias con el expresionismo de Wigman. Las primeras obras que Bausch dirige en Wuppertal como Orfeo y Eurídice (1975) y La consagración, se trazan sobre la base de una historia y una composición musical, la de Christoph Willibald Gluck y la de Stravinsky respectivamente pero luego sus obras comienzan a seguir una lógica de montaje-collage que acentúa la interrupción y la fragmentación. No obstante, esta no es la única dimensión en la que se presenta la fragmentación en las obras bauschianas. En 1976 Bausch estrena Los siete pecados capitales junto a No temas, con texto de Bertolt Brecht y música de Kurt Weil. Luego de esta obra la compañía atraviesa una crisis generada porque sus miembros se encuentran descontentos con el trabajo que realizan, lo que tempranamente lleva a Bausch a dar un giro en su forma de creación. Continúa trabajando con pocas bailarinas y bailarines desde una modalidad particular: «empecé a hacer preguntas, a formular mis propias preguntas en ese círculo, incluso qué significaba para mí una pregunta y qué para los demás» (PB, 2016:177). Este modo de creación es lo que en alguna oportunidad ella denominó su "principio de trabajo (Arbeitsprinzip)»: en lugar de indicar a quienes bailan cómo moverse y de qué forma expresar sus sentimientos más profundos, formula cientos de preguntas o palabras claves para cada obra. Desde aquí es posible considerar que Bausch al no encontrar la respuesta última a por qué nos movemos, reformula esta pregunta inicial en múltiples puntos de apoyo para las exploraciones de quienes bailan. A partir de este momento crea obras como Café Müller, Kontakthof (1978), Arien (1979) y 1980. Bausch no deja de estar comprometida con una búsqueda en torno a las emociones pero lo hace a través de su principio de trabajo y del collage, lo que involucra la interrupción y fragmentación. Así, sin dejar de tener el rol de dirección y la autoría de las obras, Bausch a través de su principio de trabajo toma distancia de una comprensión de artista creadora que impone a los bailarines cómo moverse y expresar.

La interrupción es, según ella misma comenta en una entrevista, lo que percibe como característica de la experiencia de andar por la calle, recibiendo voluntaria o involuntariamente estímulos y donde nos movilizan pluralidad de sensaciones al mismo tiempo (PB, 2016:48). Desde su modo de trabajo incorpora las experiencias y movimientos de la vida cotidiana con una pretensión de verdad (Wahrheit) buscando desarmar la ilusión o la ficción, no solo de la fantasía 
del movimiento que puede caracterizar a la danza clásica sino, de modo más amplio, de un movimiento rutinario. En esta misma línea, Bausch explica que propone que actúe el escenógrafo en Café Müller o, en otras obras, que bailarines canten - cosa que resulta difícil para ellos y para el público — porque busca «lo verdadero (Wahrheit)», y no falacias o comodidades, esto es, ver lo que ya se espera ver (PB, 2016:19).

Sobre la base de lo señalado, observo que el realismo como posicionamiento frente al problema de la representación aparece tratado de modo diferente en las consideraciones de Wigman sobre su propia danza que en la de Bausch. La primera busca «que la danza no represente sino que sea» pero para transmitir un «mensaje artístico que se lanza más allá de la realidad» a través del «movimiento natural» de los «cuerpos armoniosos» de «talentosos bailarines» que sepan mediar el mensaje de la creadora. Bausch, en cambio, pone en tensión una obra con una fuerte impronta expresionista y apoyada en una lógica lineal, La consagración, con Café Müller, la cual se formula desde el collage y su principio de trabajo. Desde aquí Bausch no busca transmitir un mensaje, no intenta ir más allá de la realidad ni pretende que las emociones escenificadas sean una buena transposición de las emociones íntimas de ella como creadora. Esta tensión entre las obras y las diferencias con el expresionismo pueden considerarse atendiendo a la impronta brechtiana en el teatro danza de Bausch y a la lectura que Benjamin realiza del teatro épico, especialmente en relación con la cuestión de la fragmentación y del montaje frente a la crisis de la representación, de la narración y de la experiencia.

\section{Interrumpir y liquidar la ilusión: la impronta del teatro brechtiano}

El teatro de Brecht conforma una referencia compartida por Benjamin y Bausch. Si bien Bausch no tematiza la influencia de dicho teatro sobre su propia danza teatro, en algunas entrevistas y en sus obras se encuentran varias pistas que conducen a su reconstrucción. Asimismo, distintos trabajos sobre su teatro danza acuerdan en que presenta una impronta brechtiana que la caracteriza (cfr. Godínez, 2017; Schilcher, 1993; Servos, 2017). En esta línea, ya se ha señalado que Bausch estrena su propia versión de Los siete pecados capitales junto a No temas, con textos de Brecht. A su vez, Bausch misma comenta que en Orfeo y Eurídice divide los roles principales en dos figuras como Brecht divide y desintegra el personaje de Ana en Los siete pecados capitales del pequeño burgués (cfr. PB, 2016:30). Además, el Tanztheater Wuppertal mantiene un vínculo con el Berliner Ensamble, lo que se puede constatar con las presentaciones y charlas del teatro danza de Bausch en el teatro fundado por Brecht (cfr. PB, 2016:90-121). Por su parte, es indiscutible la relevancia de la relación de amistad y de las discusiones intelectuales entre Benjamin y Brecht para la obra del primero, lo que se manifiesta explícitamente en sus distintos escritos sobre el teatro brechtiano (cfr. Nägele, 2006; Wizisla, 2007).

El realismo brechtiano no busca imitar la realidad sino extrañarla. Este es el objetivo principal cuando modifica la estructura del teatro clásico. No comprende la realidad de un modo estático sino de un modo dialéctico. Cuando describe e imita lo hace para confrontarse con lo imitado generando un extrañamiento de lo dado en la escena. Para esto redefine las relaciones entre la fábula y los actores, la fábula y el público, el público y los actores. En esta redefinición la operación que cumple un rol sustancial es justamente la interrupción de la acción, lo que deja expuesta la situación. Así busca eliminar la catarsis y la exoneración de las pasiones que se pretende cuando el espectador se compenetra e identifica con lo que le sucede al héroe. En el 
teatro épico hay, a diferencia del teatro clásico, un interés que es relajado y que apenas invoca la capacidad de compenetración. Más que propiciar la compenetración e ilusión, la interrupción paraliza al público y provoca asombro sobre las circunstancias generando una mirada distanciadora que da la posibilidad de descubrir la situación.

Para las distintas interrupciones Brecht involucra a otras artes, lo que no significa que se pretenda conseguir una «obra de arte total» al estilo wagneriano. No se trata de que cada arte se diluya en el conjunto, sino que unidas al arte teatral lleven adelante, cada una a su modo, la tarea que tienen en la obra. En este marco Brecht menciona el rol de la coreografía para la interrupción: un teatro que se basa en el gesto no puede prescindir de la coreografía ${ }^{4}$ (cfr. Brecht, 2018:46). El trabajo con los gestos define al teatro épico. Cuanto con más frecuencia se interrumpa al que actúa, tanto mejor se recibirá su gesto. A su vez, el gesto puede ser citado y la cita, como la cita de un texto, es un modo de interrumpir su propio contexto.

Benjamin observa en sus escritos dedicados al teatro brechtiano, que la técnica y la dinámica de la interrupción hacen que el teatro épico y el cine compartan el modo de avanzar «a golpes», es decir, el shock es la forma fundamental con la que relacionan dialécticamente el gesto con la situación, el actor con la figura que representa, el actor y el público, etcétera (Benjamin, 2009c:143). Es justamente la interrupción de la acción, decisiva para la percepción y para los nuevos medios técnicos, lo que ha llevado a Brecht, nota Benjamin, a caracterizar su teatro como épico. El espacio que se abre ante la interrupción conforma el intervalo en el que las situaciones se oponen dialécticamente y el público se ve interpelado a tomar una postura ante lo que sucede en escena.

Hacia el final de su ensayo sobre el teatro épico, Benjamin comenta que este último puede definirse fácilmente si se atiende a cómo está dispuesto el escenario: ya no se abre el espacio para la orquesta que media entre público y actores, ese «abismo» que separa «como a los muertos de los vivos» sino que al escenario se lo ha convertido en estrado (2009c:144). El teatro brechtiano sepulta aquel espacio profundo que impone la escisión entre actores y público, incrementa la nobleza del teatro y en la ópera genera «un intenso estado de embriaguez (Rausch), ese abismo que es el elemento propio del escenario que lleva aún las huellas imborrables de su origen sacro» (2009c:144).

Al menos en dos ocasiones Benjamin explica la diferencia entre el drama aristotélico y el teatro épico recurriendo a la imagen del mar: si el primero se corresponde con el movimiento de la ola que va arrastrando al público hasta llegar al final y la peripecia del héroe constituye la cresta de la ola, en el segundo, en cambio, la interrupción conforma la roca del asombro en el que se rompe el torrente de las cosas y se liquida la ilusión. El estancamiento que se produce de pronto en el flujo real de la vida es el instante en el que su curso se detiene y este movimiento es perceptible como reflujo que es el asombro (Benjamin, 2009a:119; 2009b:136).

Cuando en Café Müller se colocan sillas que entorpecen el paso de las mujeres que danzan con los ojos cerrados teniendo el escenógrafo — actuando su propio rol— que correr esas sillas para que aquellas no tropiecen, cuando entra en escena una mujer con una peluca roja o cuando la pareja repite un abrazo hasta el cansancio las operaciones que se ponen en juego son la interrupción, la fragmentación y collage. De este modo lo que sucede en la escena se ve extrañado y se desarticula la experiencia de compenetración con una única figura y la embriaguez generada por el recorrido del drama en la narración. La pregunta que desde aquí se puede 
formular es si el hecho de que se desarticule la experiencia de compenetración anula toda forma de experiencia, es decir, si es posible pensar un modo de experiencia y de narración sin continuidad, desde la fragmentación.

\section{Narración urbana}

Benjamin considera necesaria la «total falta de ilusiones sobre nuestra época» frente a la crisis de la experiencia (2007:219). Como se ve en sus escritos de la década de 1930, se ha perdido la experiencia que, vinculada a la narración oral, se caracterizaba por el gestarse en comunidad y trazar sentidos compartidos. Hacer una experiencia suponía establecer una relación en la comunicación entre las experiencias de otros y las de uno; sin embargo, la comunicación entendida como información - la prensa, el shock de la Gran Guerra, el ascenso del nazismo al poder y la sobreestimulación de la vida citadina - deterioran las condiciones de posibilidad de la narración y la experiencia. Ante esta situación Benjamin ubica a Brecht entre aquellos que reconocen la pobreza de experiencias y se deshacen de las ilusiones sobre el presente, apartándose así de la imagen del hombre tradicional. Intentar reanimar la forma de experiencia tradicional no sería más que «una forma de galvanización» (2007:218).

Desde aquí se puede leer el distanciamiento de Benjamin con respecto al expresionismo que aparece en los apuntes y notas sobre crítica cultural y literaria. En «Sobre el ratón Mickey» (1931) Benjamin menciona a Wigman, a quien es probable que haya visto bailar por compartir con ella un marco geográfico y cultural. Se refiere a ella en el relato de una conversación con Gustav Glück y Kurt Weill donde reflexionan sobre el fenómeno de las películas de Mickey Mouse. Según Benjamin, a través de esas películas «se prepara hoy la humanidad para sobrevivir a lo que es civilización», en tanto «Mickey Mouse representa la subsistencia de la criatura aún despojada de apariencia humana. Así viene a romper la jerarquía de las criaturas concebidas en directa función del ser humano». Sobre las relaciones de propiedad, «aquí aparece por primera vez que te pueden robar tu propio brazo, e incluso tu cuerpo». Estas películas muestran que «en este mundo no vale la pena tener una experiencia realmente» (Benjamin, 2017a:191. Las citas previas en el párrafo tienen la misma referencia).

Con relación a su parecido con los cuentos, es decir, con la narración tradicional, Benjamin observa que las películas de Mickey replican los sucesos centrales de la vida. La popularidad de estas películas no se debe, según Benjamin, a la mecanización ni a lo formal ni a un malentendido sino a que el público reconoce en ellas su propia vida, es decir, una vida en la que la experiencia decae. Sin embargo, estas películas carecen de un elemento crucial que es la carga simbólica de la atmósfera que les da sentido a esos sucesos. Por esto Benjamin contrapone las películas de Mickey a las obras de autores como las del dramaturgo simbolista Maurice Maeterlinck y de Wigman.

El reclamo de deshacerse de las ilusiones sobre la época y apartarse de la imagen tradicional de hombre apoyado en la interioridad se puede comprender como una respuesta al expresionismo y a la Nueva Objetividad, en la que se enmarca la referencia de Benjamin a Wigman. Son varios los textos de Benjamin en los que discute con tales corrientes culturales. Por ejemplo, en la anotación «Sobre la falsa crítica» (1930-1931) sostiene que el «expresionismo es mimetización del mero gesto revolucionario sin fundamento revolucionario», algo que persiste en la Nueva Objetividad. Ambas formas, según Benjamin, son «intentos de sobreponerse a lo que es la 
vivencia de la guerra desde el punto de vista correspondiente a la burguesía». Mientras el expresionismo intenta "hablarnos desde el punto de vista de "lo humano"», la Nueva Objetividad lo hace como presentación de «lo objetivo», manifiestos en los que «rara vez se podrá ver una época en la cual la vejez haya asfixiado a la juventud de un modo tan burdo y tan grosero» (2017b:246. Las citas previas en el párrafo tienen la misma referencia). Para Benjamin, el dadaísmo y el surrealismo han sido más revolucionarios. La crítica tiene que estar a la altura de la misión revolucionaria en lo político, esto es, analizar las relaciones ocultas, enseñar a mirar cómo en la obra el contenido objetivo y el contenido de verdad se impregnan mutuamente, donde las aporías de la estética y el conflicto entre forma y contenido se desploman (2017b:251).

No obstante, desde la lectura de Benjamin, el surrealismo tampoco ha mantenido íntegra su misión revolucionaria. En 1926 escribe una reseña para la revista Die literarische Welt sobre la versión de la obra Romeo y Julieta por parte de los Ballets Rusos, con composición musical de Constant Lambert y coreografía de Bronislava Nijinska. La reseña se titula Escándalos teatrales en París II y allí Benjamin observa que este nuevo ballet, «uno que sin duda ya no es nuevo», utiliza al surrealismo como «estimulante», suministrado por los surrealistas a cargo del decorado (Joan Miró y Max Ernst). El «escándalo» consiste en que se ha repartido un suplemento surrealista junto con el programa de mano, suplemento que declara lo siguiente: «Nosotros no aceptamos que la idea quede puesta al servicio del capital». Sin embargo, este escándalo estaba bien organizado en función del «negocio» de Diaghilev y los surrealistas no cobran por ese trabajo extra. Benjamin concluye su reseña sosteniendo que el decorado de Miró y Ernst "pone al servicio del capital sin duda no una "idea”, sino simple rutina» (2010b:405-406. Las citas precedentes tienen la misma referencia).

Retomando la contraposición que hace Benjamin entre la obra expresionista de Wigman y las películas de Mickey observamos que lo que las distingue es que en las películas de Mickey siempre hay una fuga en la que el protagonista se va de su hogar para aprender lo que es el miedo. El hogar es el de la tradición transmitida, el hogar de interior afelpado de la tradición burguesa que nos cobija y resguarda de la novedad (López, 2017). En El narrador, el que deja el hogar para aprender lo que es el miedo es una figura a través de la cual el cuento de hadas nos dispone para liberarnos del mito. Esa figura nos muestra que las cosas que tememos son escrutables, es decir, es posible deshacer el misterio y la ilusión. En lugar de resguardarse, se trataría de atreverse a abandonar el interior, lo familiar, el hogar para adentrarse en un terreno desconocido del que no sabemos prácticamente nada y que en principio parecería incluso paradójico: una subjetividad sin interioridad, una experiencia sin huellas, una narración sin continuidad.

En esta línea y siguiendo la lectura de Di Pego (2015), frente a la crisis de la experiencia y de la narración, se puede ver en el pensamiento de Benjamin un relevamiento y práctica de una forma no convencional de narración: la narración urbana. Tal tipo de narración recoge cierta herencia, es decir, ciertos rasgos, de la narración oral tradicional. Aunque en los textos de Benjamin no hay desarrollos extensos sobre este nuevo tipo de narración, sí hay algunas menciones importantes al respecto. Una de ellas aparece cuando refiere a los tres tipos de narradores, a saber, «el campesino, el marítimo y luego el urbano» (2010a:71). Otra mención significativa se encuentra en los borradores sobre novela y narración: «El narrar — todavía perdurará. Pero no en su forma "eterna", en la secreta, magnífica calidez, sino en <formas> descaradas, atrevidas, de las que aún no sabemos nada» (2010a:132). 
Esas formas descaradas y atrevidas son las que Benjamin vislumbra en sintonía con el tipo de experiencia actual y urbana que se caracteriza por la fragmentación. Las formas de narración urbana recogen la astucia e insolencia de los cuentos. Los esfuerzos de los narradores urbanos consisten en demoler la vieja precisión en la descripción, el transcurso del tiempo lineal, la vida interior, y en crear una «nueva objetividad»: «Film, corte, fotomontaje: naturalmente, todo eso apunta a una nueva objetividad (Sachlichkeit), pero sobre todo a una nueva imprecisión, que es inexorablemente suficiente para destruir la precisión heredada. Queremos: nueva precisión, nueva imprecisión, en un único argot del narrar, historias dialectales de gran ciudad» (Benjamin, 2010a:132).

\section{Consideraciones finales}

Cuando Bausch coloca seguidas Café Müller y La consagración genera una tensión entre ambas obras en buena medida porque la última se encuentra en sintonía con la propuesta del realismo expresionista mientras que la primera con el realismo del teatro brechtiano. La consagración, a través del drama, lleva al extremo el dar lugar al desarrollo continuo de los sentimientos siguiendo un libreto y una música. En cambio, Café Müller, como las obras de Bausch que se elaboran desde su principio de trabajo a partir de preguntas y palabras clave, hace que las respuestas y contribuciones sean heterogéneas e incluso provengan desde distintas corrientes artísticas propias de la formación de cada uno - aunque, por supuesto, con un entrenamiento en común-. Las huellas de la directora así como de una tradición en danza se difuminan aunque sin perderse por completo. Bausch misma señala que no lleva a escena sus vivencias, necesidades y problemas sino aquellos sentimientos y vivencias compartidas ( $\mathrm{PB}, 2016: 52$ ).

El principio de trabajo de Bausch, en el que la fragmentación ya está operando, produce asimismo una obra que enfatiza la interrupción y fragmentación de la continuidad de los sentimientos, lo que en lugar de intentar conservar modos de experiencia y de narración previos se acerca a lo que Benjamin llama narración urbana. En Café Müller no se elimina la historia pero tampoco se trata de una gran historia sino, en palabras de Bausch, de «pequeñas historias» (PB, 2016:58). La coreografía deja de concebirse fundamentalmente como secuencia de movimientos que parten de las historias de la literatura o de la música y se plantea como un montaje-collage de imágenes y pequeñas historias.

Desde esta tensión entre La consagración y Café Müller es posible precisar una de las pocas referencias de Benjamin a la danza. Benjamin no encuentra en la danza de Wigman una expresión cultural en sintonía con su diagnóstico de la situación de la experiencia y de la narración de su tiempo como sí lo encuentra, de cierta forma, en el teatro brechtiano. Basada en esto, considero que el teatro danza de Bausch, con su impronta brechtiana, se aleja de un intento de recuperar una forma de experiencia perdida para explorar las formas descaradas y atrevidas de la narración urbana. En esto consiste una de las dimensiones fundamentales del giro del Tanztheater Wuppertal en la escena de la danza alemana y su postura frente a la crisis de la representación, la narración, el movimiento y la experiencia.

\section{Notas}

10-Ton Pina Bausch. Interviews und Reden reúne el mayor número de entrevistas y conferencias ofrecidas por Pina
Bausch. Para agilizar la lectura a partir de ahora abreviaré la mención a los autores de este libro en términos de «PB». Las 
citas correspondientes al mismo así como aquellas pertenecientes a textos en idioma inglés son de traducción propia.

2 Con respecto a las escasas referencias a la danza en la tradición filosófica occidental y a la imagen que esta se ha forjado de aquella puede verse Bardet (2012) y Pouillaude (2017).

3 Si bien utilizo la traducción más usual del título «Frühlingsopfer» como «La consagración de la primavera», este también podría traducirse como «El rito de la primavera» $\mathrm{O}$ «El sacrificio de la primavera». A partir de ahora me referiré a esta obra en términos de "La consagración".

4 Si bien sería interesante indagar sobre el rol que Brecht le otorga a la danza y la coreografía en su teatro épico, en el presente trabajo no me detengo en tal cuestión.

5 Sobre la lectura ambivalente de Benjamin respecto del fenómeno de las películas del ratón Mickey véase López (2017).

\section{Referencias}

Abad Carlés, A. (2018). Historia del ballety de la danza moderna. Madrid: Alianza.

Bardet, M. (2012). Pensar con mover. Un encuentro entre danza y filosofía. Buenos Aires: Cactus.

Bausch, P. (1985). Café Müller. Suhrkamp. Video. https://www.ubu.com/dance/bausch_muller.html

Bausch, P. (2012). Le sacre du printemps. París: L’Arche. DVD y Dossier.

Bausch, P. (2013). Probe Sacre. París: L'Arche. DVD y Dossier.

Benjamin, W. (2007). Experiencia y pobreza. Obras II. Vol. 1. Madrid: Abada.

Benjamin, W. (2009a). El país en el que no se puede nombrar al proletariado. Con ocasión del estreno de ocho obras en un acto escritas por Brecht. Obras II. Vol. 2. Madrid: Abada.

Benjamin, W. (2009b). ¿Qué es el teatro épico? (Primera versión). Obras II. Vol. 2. Madrid: Abada.

Benjamin, W. (2009c). ¿Qué es el teatro épico? (Segunda versión). Obras II. Vol. 2. Madrid: Abada.

Benjamin, W. (2010a). El narrador. Santiago de Chile: Metales pesados.

Benjamin, W. (2010b). Escándalos teatrales en París II. Obras IV. Vol. 1. Madrid: Abada.

Benjamin, W. (2017a). Sobre el ratón Mickey. Obras VI. Madrid: Abada.

Benjamin, W. (2017b). Sobre la falsa crítica. Obras VI. Madrid: Abada.

Brecht, B. (2018). Brevario de estética teatral. Rosario: Cronos y Caos.

Di Pego, A. (2015). La ambivalencia de la narración en Walter Benjamin. En Naishtat, F.; Gallegos, E. y Yébenes Escardó, Z. (eds.). Ráfagas de dirección múltiple. Abordajes de Walter Benjamin (141-168). México: UAM, Unidad Cuajimalpa.

Endicott, J.A. (2012). Pina's Rite of Spring from inside. Le Sacre du printemps dossier. París: L'Arche.

Godínez, G.L. (2017). Pina Bausch. Cuerpo y danza-teatro. México: Paso de Gato.

Koldehoff, S. y Pina Bausch Fundation (2016). O-Ton Pina Bausch: Interviews und Reden. Wädenswil: Nimbus.

Lepecki, A. (2008). Agotar la danza: performance y política del movimiento. Alcalá de Henares: Universidad de Alcalá.

López, N. (2017). Devenir Mickey Mouse. El sueño tecnológico de Walter Benjamin. En García, L. (ed.). La imaginación política. Interrogantes contemporáneos sobre arte y política (257-281). Adorgué: La Cebra.

Nägele, R. (2006). Body politics: Benjamin's dialectical materialism between Brecht and the Frankfurt School. En Ferris, D.S. (ed.). The Cambridge Companion to Walter Benjamin (152-176). Cambridge: Cambridge University Press. https://doi.org/10.1017/CCOL0521793297

Pouillaude, F. (2017). Unworking Choreography: The Notion of the Work in Dance. New York: Oxford University Press.

Schilcher, S. (1993). The West German dance theatre. Paths from the twenties to the present. Choreography and dance, (3), 24-44. 
Servos, N. (2017). Pina Bausch: Danza-teatro. Madrid: Ediciones Cumbres.

Wigman, M. (2002). El lenguaje de la danza. Barcelona: Ediciones del Aguazul.

Wizisla, E. (2007). Benjamin y Brecht. Historia de una amistad. Buenos Aires: Paidós. 